\title{
Normal limits for oscillometric bronchodilator responses and relationships with clinical factors
}

\author{
Kanika Jetmalani ${ }^{1}$, Nathan J. Brown ${ }^{1,2}$, Chantale Boustany ${ }^{1,3}$, Brett G. Toelle $\mathbb{( D}^{1,4}$, Guy B. Marks $\mathbb{C}^{1,5,6}$, \\ Michael J. Abramson (10) ${ }^{7}$, David P. Johns ${ }^{8}$, Alan L. James ${ }^{9,10,11}$, Michael Hunter ${ }^{9,12}$, Arthur W. Musk ${ }^{9,10}$, \\ Norbert Berend ${ }^{1}$, Claude S. Farah $\mathbb{C}^{1,13}$, David G. Chapman $\mathbb{\mathbb { D }}^{1,14}$, Cindy Thamrin $\mathbb{\mathbb { D }}^{1}$ and Gregory G. King ${ }^{1,4}$
}

${ }^{1}$ The Woolcock Institute of Medical Research, Faculty of Medicine and Health, The University of Sydney, Sydney, NSW, Australia. ${ }^{2}$ Royal Brisbane and Women's Hospital, Emergency and Trauma Centre, Herston, QLD, Australia. ${ }^{3}$ School of Nursing, Faculty of Medicine and Health, The University of Sydney, Sydney, NSW, Australia. ${ }^{4}$ Sydney Local Health District, Sydney, NSW, Australia. ${ }^{5}$ South Western Sydney Clinical School, University of New South Wales, Sydney, NSW, Australia. ${ }^{6}$ Ingham Institute of Applied Medical Research, Sydney, NSW, Australia. ${ }^{7}$ School of Population Health and Preventive Medicine, Monash University, Melbourne, VIC, Australia. ${ }^{8}$ College of Health and Medicine, University of Tasmania, Hobart, TAS, Australia. ${ }^{9}$ Busselton Population Medical Research Institute, Busselton, WA, Australia. ${ }^{10}$ School of Medicine and Pharmacology, University of Western Australia, Perth, WA, Australia. ${ }^{11}$ Dept of Pulmonary Physiology and Sleep Medicine, Sir Charles Gairdner Hospital, Perth, WA, Australia. ${ }^{12}$ School of Population and Global Health, University of Western Australia, Perth, WA, Australia. ${ }^{13}$ Dept of Thoracic Medicine, Concord Repatriation General Hospital, Sydney, NSW, Australia. ${ }^{14}$ Dept of Respiratory Medicine, Royal North Shore Hospital, Sydney, NSW, Australia.

Corresponding author: Gregory G. King (gregory.king@sydney.edu.au)

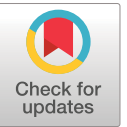

This version is distributed under the terms of the Creative Commons Attribution NonCommercial Licence 4.0. For commercial reproduction rights and permissions contact permissions@ersnet.org

This article has supplementary material available from openres.ersjournals.com

Received: 30 June 2021 Accepted: 6 July 2021



Shareable abstract (@ERSpublications)

Normative values for bronchodilator responses measured by oscillometry were derived. Responsiveness related to clinical factors and baseline function. Reactance was more sensitive in detecting bronchodilator response than spirometry mild airways disease. https://bit.ly/3wtWVeV

Cite this article as: Jetmalani K, Brown NJ, Boustany C, et al. Normal limits for oscillometric bronchodilator responses and relationships with clinical factors. ERJ Open Res 2021; 7: 00439-2021 [DOI: 10.1183/23120541.00439-2021].

\section{Abstract}

Introduction We aimed to determine normal thresholds for positive bronchodilator responses for oscillometry in an Australian general population sample aged $\geqslant 40$ years, to guide clinical interpretation. We also examined relationships between bronchodilator responses and respiratory symptoms, asthma diagnosis, smoking and baseline lung function.

Methods Subjects recruited from Sydney, Melbourne and Busselton, Australia, underwent measurements of spirometry, resistance $\left(R_{\mathrm{rs}_{6}}\right)$ and reactance $\left(X_{\mathrm{rs}_{6}}\right)$ at $6 \mathrm{~Hz}$, before and after inhalation of salbutamol $200 \mu \mathrm{g}$. Respiratory symptoms and/or medication use, asthma diagnosis, and smoking were recorded. Threshold bronchodilator responses were defined as the fifth percentile of decrease in $R_{\mathrm{rs}_{6}}$ and 95th percentile increase in $X_{\mathrm{rs}_{6}}$ in a healthy subgroup.

Results Of 1318 participants, 1145 (570 female) were analysed. The lower threshold for $\Delta R_{\mathrm{rs}_{6}}$ was $-1.38 \mathrm{cmH}_{2} \mathrm{O} \cdot \mathrm{s} \cdot \mathrm{L}^{-1}(-30.0 \%$ or $-1.42 \mathrm{Z}$-scores $)$ and upper threshold for $\Delta X_{\mathrm{rs}_{6}}$ was $0.57 \mathrm{cmH}_{2} \mathrm{O} \cdot \mathrm{s} \cdot \mathrm{L}^{-1}$ (1.36 Z-scores). Respiratory symptoms and/or medication use, asthma diagnosis, and smoking all predicted bronchodilator response, as did baseline oscillometry and spirometry. When categorised into clinically relevant groups according to those predictors, $\Delta X_{\mathrm{rS}_{6}}$ was more sensitive than spirometry in smokers without current asthma or chronic obstructive pulmonary disease (COPD), $20 \%$ having a positive response. Using absolute or Z-score change provided similar prevalences of responsiveness, except in COPD, in which responsiveness measured by absolute change was twice that for Z-score.

Discussion This study describes normative thresholds for bronchodilator responses in oscillometry parameters, including intra-breath parameters, as determined by absolute, relative and Z-score changes. Positive bronchodilator response by oscillometry correlated with clinical factors and baseline function, which may inform the clinical interpretation of oscillometry.

Introduction

Reversibility of airflow obstruction in response to a bronchodilator is a hallmark of asthma and is commonly seen in patients with chronic obstructive pulmonary disease (COPD) [1]. In patients with 
asthma, bronchodilator responsiveness is useful for diagnosis and is associated with a greater risk of future adverse events [2]. In patients with COPD, bronchodilator responsiveness is only modestly repeatable [1, 3] and correlates with: forced expiratory volume in $1 \mathrm{~s}\left(\mathrm{FEV}_{1}\right)$ improvement following oral corticosteroids [4]; with response to inhaled corticosteroid/long-acting bronchodilator combination treatment (albeit inconsistently) [5, 6]; and with lower risk of hospitalisation and mortality in patients with severe COPD [7]. Although spirometry is the gold standard for bronchodilator testing, it likely misses clinically important responses. For example, reduced hyperinflation to a short-acting bronchodilator is greater with more severe COPD, whereas the $\mathrm{FEV}_{1}$ response is less [8]. Respiratory system impedance measured by oscillometry (also known as the forced oscillation technique (FOT)) is a sensitive way to measure bronchodilator responses. There are currently insufficient data on oscillometric responses to bronchodilators in healthy subjects [9] and consequently, little data on its prevalence in disease are available.

Oscillometry involves low amplitude pressure oscillations applied to the mouth during tidal breathing. This is an important physiological difference compared with spirometry in which the forced manoeuvre of spirometry may induce airway collapse and expiratory flow limitation, or complete closure. This likely explains the poor correlation between spirometric and oscillometric bronchodilator responses [10]. The resistance of the respiratory system $\left(R_{\mathrm{rs}}\right)$ reflects airway calibre, while respiratory system reactance $\left(X_{\mathrm{rs}}\right)$ reflects predominantly the oscillatory stiffness of the respiratory system. Oscillatory stiffness is thus a dynamic stiffness (as opposed to static) and, as such, is sensitive to heterogeneously distributed airway narrowing and closure [11-13]. The literature suggests that $R_{\mathrm{rs}}$ and $X_{\mathrm{rs}}$ are more sensitive than spirometry in detecting bronchodilator responses in asthma [14-16], smokers without COPD [17] and in COPD [18], which also correlate with changes in ventilation distribution seen on lung imaging [19, 20]. However, further data on cut-off values are needed to inform clinical interpretation.

There is a single published study that includes sufficient participants to allow the reliable estimation of cut-off values. This study involved five different devices used in healthy populations across four countries [21]. While this facilitated applicability of the derived cut-offs, there were some measurement differences between devices, which complicated the interpretation of the values. Thus, we aimed to examine bronchodilator responses using a single device to derive cut-off values for bronchodilator responsiveness, and determine its relationship with respiratory symptoms, asthma diagnosis, smoking and spirometric airflow obstruction in a general population sample over the age of 40 years. We hypothesised that oscillometry would be more sensitive than spirometry in detecting bronchodilator responses, and that bronchodilator responsiveness measured by oscillometry was related to symptoms, asthma diagnosis, smoking and spirometric airflow obstruction. This study was a retrospective analysis of the data obtained in the Australian arm of the Burden of Obstructive Lung Diseases (BOLD) study, which was part of a multi-centre study of the prevalence of spirometrically determined airflow obstruction [22, 23]. Parts of this analysis have been published previously in abstract form [24] and oscillometry data from the Busselton site have been published [25].

\section{Methods}

\section{Study population}

Subjects 40 years or older were recruited randomly from three cities across Australia (Sydney in New South Wales, Melbourne in Victoria and Busselton in Western Australia). Details on how the study populations were sampled are in the supplementary material. Study operations and testing methods were consistent across sites, which were part of the global BOLD project [23], with added local tests and questionnaires. The study was approved by the Human Research Ethics Committee of the University of Sydney (ref. 12-2006/9724). All subjects gave informed, written consent.

\section{Study design}

This was a cross-sectional study of oscillometric bronchodilator responses in the BOLD cohort in which the limits of responsiveness in healthy subjects were defined, then applied to the remainder of the cohort to determine the prevalence of increased bronchodilator responsiveness and its relationships with symptoms, doctor diagnosis of asthma and smoking. All subjects underwent oscillometry and spirometry measurements, in that order, at baseline and $15 \mathrm{~min}$ after the administration of $200 \mu \mathrm{g}$ salbutamol administered by metered-dose inhaler through a spacer. Participants had all respiratory medications withheld on the day of testing; with short-acting bronchodilator inhalers for $\geqslant 6 \mathrm{~h}$ before testing. Respiratory symptoms, medication use and smoking history were obtained using the BOLD core questionnaire. 
To define cut-off values we identified a healthy group (Healthy Asym $_{\text {) }}$ as those with no respiratory symptoms or inhaled medications use in the past year, no doctor diagnosis ever of either asthma or COPD ever, currently not smoking and having less than 10 pack-years past smoking. Spirometry was not used to define this group as we wanted to remain consistent with definitions used in studies of normal spirometry, such as the Global Lung Function Initiative (GLI). Normative equations for oscillometry parameters were developed from this healthy group, based on previously published methodology [25], from which Z-scores for bronchodilator responsiveness were calculated.

\section{Oscillometry}

The oscillometry device was built in-house and has been described previously [26]. A detailed description is presented in the supplementary material. In brief, a multi-frequency pressure oscillation (6, 11 and $19 \mathrm{~Hz}$ ) was imposed at the mouth. After establishing stable tidal breathing, a single 60-s recording was acquired with subjects supporting their own cheeks. Only the impedance parameters at $6 \mathrm{~Hz}$ were analysed in this study. Quality control procedures were applied as previously described [27]. Resistance was expressed as the mean across the entire recording $\left(R_{\mathrm{rs}_{6}}\right)$, and also separately for inspiration only $\left(R_{\mathrm{rs}_{6} \text {.insp }}\right)$. Similarly, reactance was expressed as the mean $\left(X_{\mathrm{rs}_{6}}\right)$ and $X_{\mathrm{rs}_{6, \text { insp }}}$. Mean $X_{\mathrm{rs}_{6, \text { insp }}}$ minus mean expiratory $X_{\mathrm{rs}_{6}}$ was calculated as an index of expiratory flow limitation (EFLi) [28]. Z-scores were calculated for each pre-bronchodilator and post-bronchodilator measurement, for each participant, based on age- and sex-specific expected mean and standard deviation values in the Healthy Asym $_{\text {group. }}$

\section{Spirometry}

Spirometry was performed according to American Thoracic Society/European Respiratory Society Task Force criteria [29], using an EasyOne Plus hand-held spirometer (NDD Medical Technologies, Andover, MA, USA). All spirograms were reviewed by one study investigator (D.P. Johns) who assigned a standardised quality score. The highest recorded $\mathrm{FEV}_{1}$ and forced vital capacity (FVC) from acceptable trials were used in the analysis. Prediction equations of the GLI [30] were used.

\section{Bronchodilator responses}

The bronchodilator responses $(\Delta)$ were calculated as post-bronchodilator values minus baseline (pre-bronchodilator) values, and expressed as absolute change, proportional (\%) change from baseline and


occur, even for transformed data, absolute and Z-score changes only were used. A negative $\Delta R_{\mathrm{rS}_{6}}$ indicated decrease (the expected response), therefore the lower limit of normal (LLN) was defined as the fifth percentile of bronchodilator response in the Healthy $y_{\text {Asym }}$ group. A positive $\Delta X_{\mathrm{rs}_{6}}$ indicated an increase (the expected response), therefore the upper limit of normal (ULN) was defined as the 95th percentile. Positive bronchodilator responsiveness in either $\mathrm{FEV}_{1}$ or $\mathrm{FVC}$ was defined as an increase of $\geqslant 12 \%$ and $\geqslant 200 \mathrm{~mL}$.

\section{Statistical analyses}

The data were analysed using SPSS software (IBM, Armonk, NY, USA; version 21). Paired t-tests and the Wilcoxon signed-rank test were used to compare baseline and post-bronchodilator lung function as appropriate. Natural logarithm and exponential transformations were used to normalise $R_{\mathrm{rs}_{6}}$ and $X_{\mathrm{rs}_{6}}$ distributions, respectively, in the healthy group. Multiple linear regressions were used to define normative equations as performed previously [25]. Spearman correlations were used to evaluate the relationships between bronchodilator responses and potential anthropometric predictors (age, sex, height and body mass index (BMI)), baseline lung function, and clinical predictors (respiratory symptoms, asthma diagnosis and smoking history).

\section{Results}

Of 1318 subjects, 163 were excluded due to incomplete data, 10 had highly disparate $R_{\mathrm{rs}_{6}}$ and $X_{\mathrm{rs}_{6}}$ values indicating artefact, leaving 1145 (86.9\%) with complete questionnaire and technically satisfactory pre-bronchodilator and post-bronchodilator FOT and spirometry data. The anthropometric characteristics of the entire cohort are described in table 1 . The anthropometric characteristics of the healthy subgroup of the entire cohort are also shown. A smoking history of $\geqslant 10$ pack-years was reported by $27.9 \%$ (320 out of 1145), while $10.4 \%$ (119 out of 1145 ) had obstructed baseline spirometry and $7.1 \%$ (81 out of 1145 ) had obstructed post-bronchodilator spirometry. Positive spirometric bronchodilator responses occurred in $6.6 \%$ (75 out of 1145). The post-bronchodilator spirometry and all oscillometric parameters, were all significantly different compared with baseline (figure 1).

\section{Bronchodilator responses in healthy subjects}

There were 577 subjects in the Healthy Asym group (table 1). Their baseline and post-bronchodilator spirometry and oscillometry parameters are shown in table E1. This shows that there were minimal but 


\begin{tabular}{|c|c|c|}
\hline & Entire cohort ${ }^{\#}$ & Healthy $_{\text {Asym }}$ \\
\hline Subjects & 1145 & 577 \\
\hline Age, years & $61.3 \pm 12.4$ & $60.6 \pm 12.5$ \\
\hline Male/female & $570 / 575$ & $244 / 333$ \\
\hline Height, m & $1.68 \pm 0.09$ & $1.67 \pm 0.09$ \\
\hline Smoking, pack-years & $0.0(0.0-12.0)$ & $0(0.0-0.75)$ \\
\hline $\mathrm{BMI}, \mathrm{kg} \cdot \mathrm{m}^{-2}$ & $27.8 \pm 4.6$ & $26.8 \pm 4.0$ \\
\hline $\mathrm{FEV}_{1}, \mathrm{Z}$-score & $-0.24 \pm 1.03$ & $0.1 \pm 0.9$ \\
\hline $\mathrm{FEV}_{1} / \mathrm{FVC}, \mathrm{Z}$-score & $-0.46 \pm 0.96$ & $-0.3 \pm 0.8$ \\
\hline$R_{\mathrm{rs}_{6}}, \mathrm{cmH}_{2} \mathrm{O} \cdot \mathrm{s} \cdot \mathrm{L}^{-1}$ & $3.29(2.65-4.15)$ & $3.10(2.53,3.78)$ \\
\hline$X_{\mathrm{rs} 6}, \mathrm{cmH}_{2} \mathrm{O} \cdot \mathrm{s} \cdot \mathrm{L}^{-1}$ & $-0.45(-0.83--0.22)$ & $-0.39(-0.66--0.18)$ \\
\hline $\mathrm{EFLi}, \mathrm{cmH}_{2} \mathrm{O} \cdot \mathrm{s} \cdot \mathrm{L}^{-1}$ & $-0.12(-0.27-0.89)$ & $-0.15(-0.27--0.02)$ \\
\hline
\end{tabular}

statistically significant bronchodilator-associated changes in $\mathrm{FEV}_{1}, \mathrm{FVC}$ and $\mathrm{FEV}_{1} / \mathrm{FVC}$ ratio, and all oscillometry parameters. The normative equations for oscillometry that were derived from this group to determine Z-scores, are listed in table E2 and the normative thresholds for bronchodilator responses are given in table 2. The LLN of $\Delta R_{\mathrm{rs}}$ parameters and ULN for $\Delta X_{\mathrm{rs}}$ parameters are also provided in table 2. The bronchodilator responses in all other subjects (table 2) were significantly different for all oscillometry and spirometry parameters, compared with the Healthy Asym group.

\section{Predictors of bronchodilator responses}

The anthropometric (sex, height and BMI), clinical (symptoms, asthma diagnosis and smoking history) and baseline lung function $\left(R_{\mathrm{rs}_{6}}, X_{\mathrm{rs}_{6}}\right.$ and spirometry Z-scores) predictors of bronchodilator responses for the entire cohort are shown in table E3. Male patients had larger $\Delta X_{\mathrm{rs}_{6}}$ Z-score and $\Delta \mathrm{FVC}$, but changes were very small and clinically insignificant. Higher BMI was associated with larger $\Delta R_{\mathrm{rs}_{6}}, \Delta R_{\mathrm{rs}_{6, \text { insp }}}$, all $\Delta X_{\mathrm{rs}_{6}}$ parameters and $\triangle \mathrm{FVC}$. Asthma diagnosis and respiratory symptoms were associated with larger bronchodilator responses in all but one of the spirometry and oscillometry parameters ( $\triangle \mathrm{EFLi}$ ). Smoking history was associated with larger bronchodilator responses in spirometry and all oscillometry parameters. Greater impairment of baseline oscillometry and spirometry parameters predicted greater bronchodilator responses in all parameters except for $\mathrm{FEV}_{1} / \mathrm{FVC}$ not predicting $\triangle \mathrm{FVC}$ (table E3).
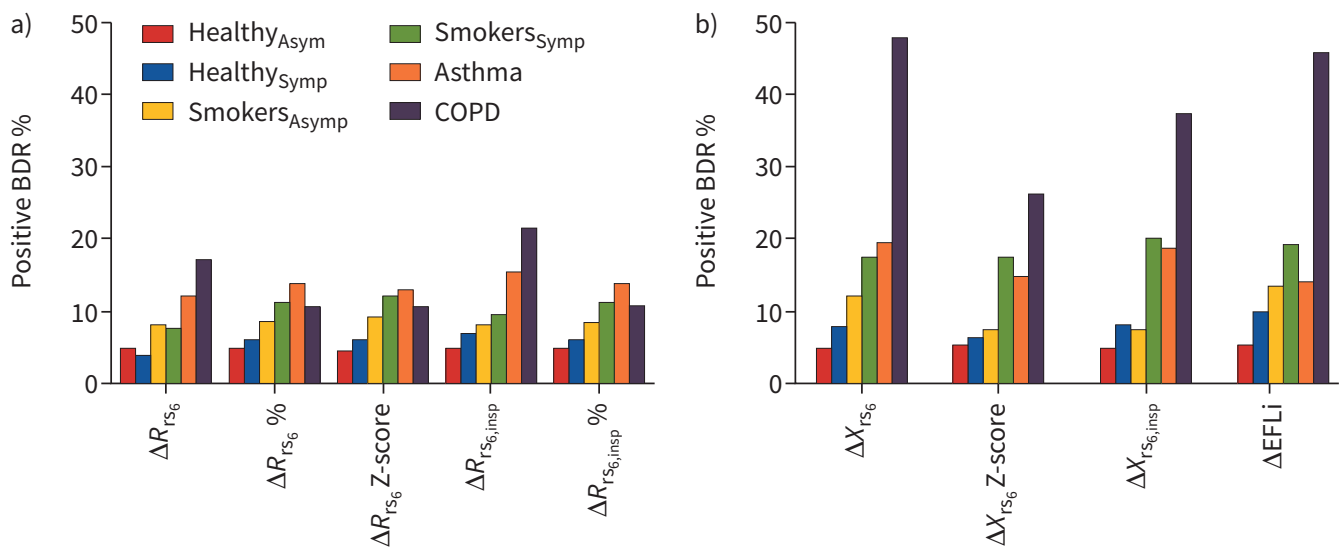

FIGURE 1 The bronchodilator-induced changes in a) resistance and b) reactance parameters of the respiratory system, for each of the clinically defined groups. BDR: bronchodilator response; $\Delta$ : post-bronchodilator minus pre-bronchodilator change; $R_{\mathrm{rs}_{6}}$ : resistance of the respiratory system measured at $6 \mathrm{~Hz}$; insp: inspiratory; $X_{\mathrm{rs}_{6}}$ : reactance of the respiratory system measured at $6 \mathrm{~Hz}$; EFLi: expiratory flow limitation index; Asym; asymptomatic: Symp: symptomatic. 
TABLE 2 Bronchodilator responses for resistance and reactance of the respiratory system and spirometry parameters in the healthy asymptomatic (Healthy Asym $_{\text {) }}$ group and remainder

\begin{tabular}{|c|c|c|c|}
\hline Parameter & Healthy $_{\text {Asym }}(n=577)$ & LLN or ULN & Remainder $(n=568)$ \\
\hline$\Delta R_{\mathrm{rs}_{6}}, \mathrm{cmH}_{2} \mathrm{O} \cdot \mathrm{s} \cdot \mathrm{L}^{-1}$ & $-0.23(-0.57-0.04)$ & LLN -1.38 & $-0.36(-0.81--0.01)$ \\
\hline$\Delta R_{\mathrm{rs}_{6}}, \%$ & $-6.4(-17.2-1.3)$ & LLN -30.0 & $-11.3(-20.4--0.2)$ \\
\hline$\Delta R_{\mathrm{rs}_{6}}$, Z-score & $-0.31(-0.73-0.03)$ & LLN -1.42 & $-1.1(-2.4--0.3)$ \\
\hline$\Delta R_{\mathrm{rS}_{\mathrm{G}} \text {,insp }}, \mathrm{CmH}_{2} \mathrm{O} \cdot \mathrm{s} \cdot \mathrm{L}^{-1}$ & $-0.31(-0.67--0.04)$ & LLN -1.38 & $-0.41(-0.93--0.11)$ \\
\hline$\Delta R_{\mathrm{rs}_{6, \mathrm{insp}}}, \%$ & $-8.5(-20.7-1.3)$ & LLN -42.9 & $-12.7(-25.6--0.2)$ \\
\hline$\Delta X_{\mathrm{rs}_{6}, \mathrm{CmH}_{2}} \mathrm{~cm}_{2} \mathrm{O} \cdot \mathrm{s} \cdot \mathrm{L}^{-1}$ & $0.09 \pm 0.26$ & ULN 0.57 & $0.28 \pm 0.57$ \\
\hline$\Delta X_{\mathrm{rs}_{6}}^{\circ}, \mathrm{Z}$-score & $0.25 \pm 0.67$ & ULN 1.36 & $0.5 \pm 0.8$ \\
\hline$\Delta X_{\mathrm{rs}_{\mathrm{Ginss}},}, \mathrm{cmH}_{2} \mathrm{O} \cdot \mathrm{s} \cdot \mathrm{L}^{-1}$ & $0.12 \pm 0.23$ & ULN 0.53 & $0.22 \pm 0.40$ \\
\hline$\Delta \mathrm{EFLi}, \mathrm{CmH}_{2} \mathrm{O} \cdot \mathrm{s} \cdot \mathrm{L}^{-1}$ & $0.039 \pm 0.281$ & LLN -0.37 & $-0.099 \pm 0.592$ \\
\hline$\Delta \mathrm{FEV}_{1}, \mathrm{~mL}$ & $76 \pm 119$ & & $106 \pm 135$ \\
\hline$\Delta \mathrm{FVC}, \mathrm{mL}$ & $34 \pm 176$ & & $39 \pm 208$ \\
\hline
\end{tabular}

Data are presented as median (interquartile range) or mean \pm sD, unless otherwise stated. Responses for resistance are defined as the fifth percentiles and upper limits of normal (ULNs) for reactance are defined as the 95th percentiles. LLN: lower limit of normal; $\Delta$ : post-bronchodilator minus pre-bronchodilator change; $\operatorname{Rrs}_{6}$ : resistance of the respiratory system measured at $6 \mathrm{~Hz}$; insp: inspiratory; $X_{\mathrm{rs}}$ : reactance of the respiratory system measured at $6 \mathrm{~Hz}$; EFLi: expiratory flow limitation index; $\mathrm{FEV}_{1}$ : forced expiratory volume in $1 \mathrm{~s}$; FVC: forced vital capacity. $\mathrm{p}<0.002$ for Healthy ${ }_{\text {Asym }}$ compared with remainder all $R_{\mathrm{rs}_{6}}$ parameters (Mann-Whitney); $\mathrm{p}<0.001$ Healthy $\mathrm{Asym}_{\text {Asm }}$ compared with remainder for all $X_{\mathrm{rs}_{6}}$ parameters (t-test).

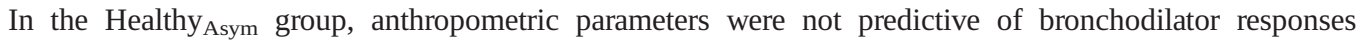
(tables E4 and E5). However, baseline $R_{\mathrm{rs}_{6}}$ and $X_{\mathrm{rs}_{6}}$ Z-scores predicted all $\Delta R_{\mathrm{rs}_{6}}$ and $\Delta X_{\mathrm{rs}_{6}}$ parameters (except $\Delta \mathrm{EFLi}$ and $\Delta R_{\mathrm{rs}_{6 \text { insp }}}$ (\%) in men). Baseline $\mathrm{FEV}_{1}$ and $\mathrm{FEV}_{1} / \mathrm{FVC}$ Z-scores predicted $\Delta \mathrm{FEV}_{1}$ and all $\Delta R_{\mathrm{rs}_{6}}$ parameters in women, while only $\mathrm{FEV}_{1} / \mathrm{FVC} \mathrm{Z}$-scores were predictive in men.

\section{Clinical context of bronchodilator responses}

Given the above associations with asthma diagnosis, symptoms and/or medication use, smoking history and airflow obstruction, the prevalence of bronchodilator responses was determined for clinical groups based on those parameters, to provide clinical context. Consequently, five mutually exclusive groups were

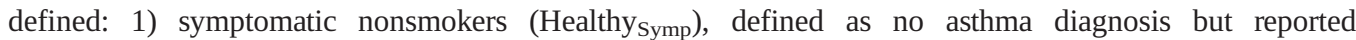
respiratory symptoms in the last year and <10 pack-years smoking; 2) asymptomatic smokers (Smokers ${ }_{\text {Asym }}$ ), with no respiratory symptoms in the last year and no asthma diagnosis but $\geqslant 10$ pack-years smoking history and $\mathrm{FEV}_{1} / \mathrm{FVC}$ ratio Z-score $\geqslant L L N ; 3$ ) symptomatic smokers (Smokers Symp $_{\text {), the same as }}$ Smokers $_{\text {Asym }}$ but reporting respiratory symptoms; 4) nonsmokers with current asthma, defined as any past asthma diagnosis and reporting respiratory symptoms and/or respiratory medication use in the last year, and $<10$ pack-years smoking; 5) smokers with fixed airflow obstruction (“COPD”), defined as $\geqslant 10$ pack-years smoking history and post-bronchodilator $\mathrm{FEV}_{1} / \mathrm{FVC}$ ratio Z-score <-1.645). Therefore, COPD subjects could have a doctor diagnosis of asthma (present in 20 out of 46 subjects) and subjects with asthma could have an abnormal $\mathrm{FEV}_{1} / \mathrm{FVC}$ ratio (32 and 20 out of 122 had reduced Z-scores pre-bronchodilator and post-bronchodilator, respectively). The definition of these groups is shown in figure 2.

The anthropometric characteristics of each group are shown in table E6, their median bronchodilator changes are shown in table E7 and the prevalence of abnormal baseline function in table E8. The percentage of positive bronchodilator responsiveness in each group is shown in table 3 and in figure 1 . The

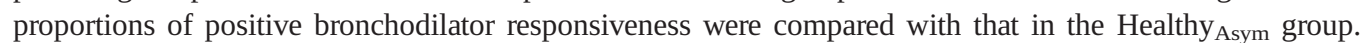
The Healthy Symp $_{\text {group were similar. Smokers }}$ ssym $_{\text {had }}$ more positive bronchodilator responsiveness in $\Delta X_{\mathrm{rs}_{6}}$ (absolute change) and $\Delta \mathrm{EFLi}$, but not in spirometry; Smokers ${ }_{\text {Symp }}$ had more positive bronchodilator responses in all of the $\Delta X_{\mathrm{rs}_{6}}$ parameters and in $\Delta \mathrm{FEV}_{1}$. In the asthma and COPD groups, bronchodilator responsiveness was increased for almost all parameters (except $\Delta R_{\mathrm{rs}_{6}} \%$ and $\Delta R_{\mathrm{rs}_{6}}$ Z-score in COPD). The

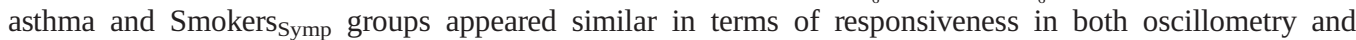
spirometry. Notably, 109 out of 122 (89.3\%) of people with asthma reported wheeze in the previous 12 months. Bronchodilator responsiveness was greatest in COPD, in $\Delta X_{\mathrm{rs}_{6}}$ expressed as absolute change or $\triangle E F L i$, of whom approximately half exhibited positive responses. Positive $\Delta \mathrm{FEV}_{1}$ responsiveness was also demonstrated in about a third of this group.

Except in the COPD group, the prevalence of responsiveness was similar for each of the $\Delta R_{\mathrm{rs}_{6}}$ and $\Delta X_{\mathrm{rs}_{6}}$ parameters. In COPD, absolute changes resulted in more positive responders than either relative or Z-score 




FIGURE 2 Disposition into clinical groups. See Results section for definition of groups. Asym: asymptomatic; Symp: symptomatic.

changes $(\mathrm{p}<0.01$, chi-squared test), likely due to their more severe baseline obstruction. Also, responsiveness was generally more frequent for $X_{\mathrm{rs}_{6}}$ than for $R_{\mathrm{rs}_{6}}$ parameters in smoking and disease groups, particularly in COPD (figure 1 and table 3). Bronchodilator responsiveness was more prevalent for $\Delta X_{\mathrm{rs}_{6}}$ parameters, compared with $\Delta \mathrm{FEV}_{1}$, in the symptomatic and smoking groups, but not in the asthma or COPD groups (table 4).

\section{Discussion}

In summary, we have defined lower and upper limits of bronchodilator responsiveness for $R_{\mathrm{rs}_{6}}$ and $X_{\mathrm{rs}_{6}}$ parameters, respectively, from a healthy, community cohort, which included intra-breath parameters and changes in Z-scores [9], to allow us to compare bronchodilator responsiveness measured by oscillometry to responsiveness measured by spirometry. Our thresholds for bronchodilator responsiveness measured by oscillometry were almost identical to published values [21] and oscillometry was more sensitive than spirometry in symptomatic nonsmokers and in both symptomatic and asymptomatic smokers who had normal spirometry. We also found bronchodilator responsiveness was related to asthma diagnosis, respiratory symptoms, smoking history and baseline airway function (both spirometry and oscillometry). In five clinical groups defined according to those factors, oscillometric bronchodilator responsiveness

TABLE 3 Percentage of positive bronchodilator responses for resistance and reactance of the respiratory system, and spirometry parameters, for each of the clinical groups

\begin{tabular}{|c|c|c|c|c|c|c|}
\hline & Healthy $_{\text {Asym }}(n=577)$ & Healthy $_{\text {symp }}(n=126)$ & Smokers $_{\text {Asym }}(n=159)$ & Smokers $_{\text {Symp }}(n=115)$ & Asthma $(n=122)$ & COPD $(n=46)$ \\
\hline$\Delta R_{\mathrm{rs}_{6}}(\mathrm{abs})$ & 4.9 & 4.0 & 8.2 & 7.8 & $12.3^{*}$ & $17.4^{\#}$ \\
\hline$\Delta R_{\mathrm{rs}_{6}}(\%)$ & 5.0 & 6.3 & 8.8 & 11.3 & $13.9^{*}$ & 10.9 \\
\hline$\Delta R_{\mathrm{rs}_{6}}(\mathrm{Z}$-score $)$ & 4.5 & 6.3 & 9.4 & $12.2^{\star}$ & $13.1^{*}$ & 10.9 \\
\hline$\Delta R_{\mathrm{rS}_{6, \text { inso }}}(\mathrm{abs})$ & 4.9 & 7.1 & 8.2 & 9.6 & $15.6^{*}$ & $21.7^{\star}$ \\
\hline$\Delta R_{\mathrm{rs}_{6, \text {,insp }}}(\%)$ & 4.9 & 6.3 & 8.8 & 11.3 & $13.9^{*}$ & 10.9 \\
\hline$\Delta X_{\mathrm{rs}_{6}}$ (abs) & 4.9 & 7.9 & $11.9^{\star}$ & $17.4^{*}$ & $19.7^{\star}$ & $47.8^{\circ}$ \\
\hline$\Delta X_{\mathrm{rs}_{6}}(\mathrm{Z}$-score $)$ & 5.0 & 6.3 & 7.5 & $17.4^{\star}$ & $14.8^{\star}$ & $26.1^{+}$ \\
\hline$\Delta X_{\mathrm{rs}_{6, \text { insp }}}(\mathrm{abs})$ & 4.7 & 7.9 & 7.5 & $20.0^{\star \S}$ & $18.9^{*}$ & $37.0^{+}$ \\
\hline$\Delta \mathrm{EFLi}$ (abs) & 4.9 & 9.5 & $13.2^{*}$ & $19.1^{*}$ & $13.9^{\star}$ & $45.7^{\circ 1}$ \\
\hline$\Delta \mathrm{FEV}_{1}(\%)$ & 2.3 & 0.8 & 1.9 & $9.6^{\#}$ & $17.2^{+}$ & $30.4^{f}$ \\
\hline$\Delta \mathrm{FVC}(\%)$ & 1.4 & 0.8 & 0.6 & 5.2 & $9.8^{+}$ & $30.4^{4}$ \\
\hline
\end{tabular}

Asym: asymptomatic; Symp: symptomatic; $\Delta$ : post-bronchodilator minus pre-bronchodilator change; Rrs 6 : resistance of the respiratory system measured at $6 \mathrm{~Hz}$; abs: absolute; insp: inspiratory; $\mathrm{X}_{\mathrm{rs}_{6}}$ : reactance of the respiratory system measured at $6 \mathrm{~Hz}$; EFLi: expiratory flow limitation index; $\mathrm{FEV}_{1}$ : forced expiratory volume in $1 \mathrm{~s}$; FVC: forced vital capacity. ${ }^{*}$ : $\mathrm{p}<0.05$ compared with Healthy Asym $_{\text {only }}$ (Z-test with Bonferroni correction);



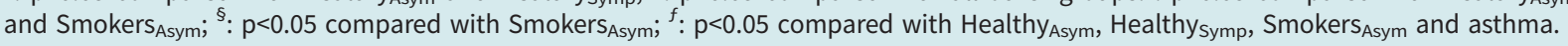


TABLE 4 Unadjusted p-values from comparisons of the proportion of bronchodilator responsiveness within groups, measured by change in $(\Delta)$ reactance of the respiratory system measured at $6 \mathrm{~Hz}\left(X_{\mathrm{rs}_{6}}\right)$ parameters versus change in forced expiratory volume in $1 \mathrm{~s}$, in healthy but symptomatic (Symp), smoking, asthmatic and COPD groups

\begin{tabular}{|c|c|c|c|c|c|}
\hline & Healthy $_{\text {symp }}(n=126)$ & Smokers $_{\text {Asym }}(n=159)$ & Smokers $_{\text {Symp }}(n=115)$ & Asthma ( $n=122)$ & $\operatorname{COPD}(n=46)$ \\
\hline$\Delta X_{\mathrm{rs}_{6}}(\mathrm{abs})$ & $0.012^{\star}$ & $0.001^{\star}$ & 0.108 & 0.678 & 0.077 \\
\hline$\Delta X_{\mathrm{rs}_{6}}$ (Z-score) & 0.039 & 0.035 & 0.078 & 0.648 & 0.774 \\
\hline$\Delta X_{\mathrm{rs}_{6, \text { insp }}}(\mathrm{abs})$ & $0.012^{\star}$ & 0.035 & $0.023^{*}$ & 0.824 & 0.549 \\
\hline$\Delta \mathrm{EFLi}$ (abs) & $0.003^{*}$ & $0.0003^{*}$ & 0.043 & 0.556 & 0.118 \\
\hline
\end{tabular}

Asym: asymptomatic; abs: absolute; insp: inspiratory; EFLi: expiratory flow limitation index. Comparisons were by McNemar tests. *: significant $p$-values after Benjamini-Hochberg adjustment for multiple comparisons, using $\alpha=0.10$ ( $10 \%$ false discovery rate).

quantified as absolute, percentage and Z-score changes, produced similar outcomes, except in COPD for which responses measured as absolute changes were about twice as frequent as measured by relative or Z-score change. This was likely due to the dependence of bronchodilator responsiveness on baseline values.

Only one of several published studies on bronchodilator responses in healthy subjects [21, 31-33] had sufficient numbers to reliably define upper and lower limits of bronchodilator responses [9, 21], although not for intra-breath parameters and not expressed as changes in Z-scores, as we produced. These normal limits were derived from pooled measurements from five different devices, in a slightly younger population than the present study. Despite these differences, our lower limit of bronchodilator response for $R_{\mathrm{rs}_{6}}$ $\left(-1.38 \mathrm{cmH}_{2} \mathrm{O} \cdot \mathrm{s} \cdot \mathrm{L}^{-1}\right.$ or $\left.-30.0 \%\right)$ and upper limit for $X_{\mathrm{rs}_{6}}\left(0.57 \mathrm{cmH}_{2} \mathrm{O} \cdot \mathrm{s} \cdot \mathrm{L}^{-1}\right)$ are practically identical to that reported in the study by OostveEN et al. [21] $\left(R_{\mathrm{rs}_{6}}-1.28 \mathrm{cmH}_{2} \mathrm{O} \cdot \mathrm{s} \cdot \mathrm{L}^{-1}\right.$ or $-31.5 \%$ and $X_{\mathrm{rs}_{6}}$ $0.47 \mathrm{cmH}_{2} \mathrm{O} \cdot \mathrm{s} \cdot \mathrm{L}^{-1}$ ). This suggests that these cut-points based on absolute and relative change in mean $R_{\mathrm{rs}}$ and absolute change in $X_{\mathrm{rs}_{6}}$ are fairly robust given their consistency across different populations and devices. Although increasing BMI predicted lower bronchodilator response in $R_{\mathrm{rs}_{6}}$ in healthy men, it was marginal (table E5) and did not predict responses in women. Correction for BMI was therefore not performed in determining normal responsiveness.

Bronchodilator responsiveness of all oscillometry parameters (and for $\Delta \mathrm{FEV}_{1}$ and $\triangle \mathrm{FVC}$ ) correlated with baseline values for $R_{\mathrm{rs}_{6}}, X_{\mathrm{rs}_{6}}$ and spirometry. This suggests that bronchodilator responses should be expressed as relative change [34]. However, we did not use relative change for $X_{\mathrm{rs}_{6}}$ parameters because of the very large values and highly skewed distribution that resulted from values that were close to zero. However, use of the absolute, relative or Z-score changes in $R_{\mathrm{rs}_{6}}$ or $X_{\mathrm{rs}_{6}}$ did not affect the prevalence of bronchodilator responders in groups other than COPD, therefore these cut-offs could be used interchangeably. In the COPD group, when $\Delta X_{\mathrm{rs}_{6}}$ was expressed as absolute change, positive bronchodilator responsiveness was about twice that responsiveness expressed as Z-score change. This is likely due to the strong dependence of $\Delta X_{\mathrm{rs}_{6}}$, expressed as absolute change, on baseline values. This may be explained by $X_{\mathrm{rs}_{6}}$ being sensitive to airway closure and heterogeneous severe narrowing that is common in COPD [11-13, 35, 36]. Even small decreases in bronchoconstriction could alleviate airway severe narrowing and closure, but would have a large effect in improving $X_{\mathrm{rs}_{6}}$. Thus, bronchodilator responses should arguably be expressed as either relative or Z-score change, given their dependence on baseline function. However, it is also possible that the high prevalence of bronchodilator responsiveness measured by $\Delta X_{\mathrm{rs}_{6}}$ as absolute change may be clinically meaningful; this requires further study.

Showing the prevalence of bronchodilator responsiveness by groups was to provide clinical context. Disease or diagnostic labels are arbitrary and our primary aim was not to investigate disease or diagnostic label differences. Nevertheless, there were some clinically interesting observations. The asthma group was large (10.7\%) and, despite being a community sample with normal baseline function, oscillometric bronchodilator responsiveness was common in nearly 20\%. In the COPD group, bronchodilator responsiveness was present in nearly half according to either $\Delta X_{\mathrm{rs}_{6}}$ or spirometry. This could be related to asthma diagnoses in 20 out of 46 in addition to their smoking and, arguably, they may justifiably have an asthma/COPD overlap label. Although BMI predicted $\Delta X_{\mathrm{rs}}$ responses in the whole cohort (table E3), it may be explained by its association with symptoms and smoking since Healthy Symp $_{\text {and both smoking }}$ groups were heavier than the reference group (tables E4 and E5). Despite their normal spirometry, 18.2\% of asymptomatic smokers and $31.3 \%$ of symptomatic smokers had abnormal baseline oscillometry (defined as abnormality in either $R_{\mathrm{rs}_{6}}$ or $X_{\mathrm{rs}_{6}}$ ). Furthermore, their bronchodilator responsiveness in $X_{\mathrm{rs}_{6}}$ parameters 
(up to 20\%) was about twice that of spirometry. There may be value in exploring potential clinical correlations in symptomatic smokers, given the evidence of their increased morbidity [37].

Because of the greater bronchodilator responsiveness in oscillometry in the COPD and asthma groups, in particular in $X_{\mathrm{rs}}$, the concordance between the bronchodilator responses measured by oscillometry and spirometry was only fair $(\kappa=0.21-0.40)$ while being poor or slight in the other groups. This is consistent with published studies [10, 21, 38, 39]. In COPD, this difference could possibly be due to oscillometry being more sensitive to smoking-related lung damage than spirometry. The basis of the differences is unknown but may reflect the different manoeuvres used during spirometry and oscillometry measurements. In a tertiary asthma clinic study [15], $\kappa$ between spirometry and $X_{\mathrm{rS}_{5}}$ was 0.45 , perhaps due to a wider range of lung function impairment. However, oscillometric bronchodilator responses related more strongly to asthma control than spirometry [15]. Discordant bronchodilator responsiveness between oscillometry and spirometry could be clinically important, i.e. complementary information, but this also needs further study.

A potential limitation of this study was the participant ages of 40 years or older, which meant that these findings could not be applied to younger subjects. The oscillometry device was a proprietary device and, therefore, not used clinically elsewhere, and our use of $6 \mathrm{~Hz}$ and $19 \mathrm{~Hz}$ is nonstandard (usually $5 \mathrm{~Hz}$ and $19 \mathrm{~Hz}$ ). Theoretically, any differences in measurements associated with different frequencies are likely to be insignificant. We have also compared our device with three other commercial oscillometry devices and showed that, while $R_{\mathrm{rs}_{6}}$ was comparable between devices, there was greater variability in $X_{\mathrm{rs}_{6}}$ [40]. These findings are consistent with other studies comparing those same devices [21, 41] but it should also be noted that there are greater disparities in $X_{\mathrm{rs}}$ measurements between other oscillometry devices [41]. Nevertheless, any small differences in measurements between devices are unlikely to affect bronchodilator responses given the within-session changes being measured. The COPD group was small (46 out of 1145) and approximately half also had an asthma diagnosis. Given the many COPD phenotypes, our findings would not be generalisable to COPD or to other smoking-related airways diseases.

In conclusion, we have defined normative values for bronchodilator responses for oscillometry parameters, in a large, well characterised healthy population sample of 40 years and older. These thresholds are potentially useful to inform interpretation of oscillometry in airway disease. Bronchodilator responsiveness was associated with respiratory symptoms, asthma diagnosis and smoking history. $\Delta X_{\mathrm{rs}_{6}}$ may be a particularly sensitive measure of airway dysfunction in smokers with normal spirometry. For the purposes of clinical interpretation, given the strong dependence of bronchodilator response on baseline oscillometric or spirometric function, it may be more appropriate to express responses as either relative or Z-score change. The clinical significance of oscillometric bronchodilator responsiveness, particularly in relation to disease phenotypes and treatable traits, needs further study, given that the fair concordance with spirometry suggests potential complementarity.

Acknowledgements: We would like to acknowledge the work of the BOLD teams from Sydney, Melbourne and Busselton: Tessa Bird, Paola Espinel, Peta Grayson, Joan Green, Kate Hardaker, Elspeth Inglis, Marsha Ivey, Christine Jenkins, Angela Lewis, Joan Raven and Wei Xuan.

Provenance: Submitted article, peer reviewed.

Conflict of interest: K. Jetmalani is a part-time employee of GlaxoSmithKline. N.J. Brown has nothing to disclose. C. Boustany has nothing to disclose. B.G. Toelle has nothing to disclose. G.B. Marks has nothing to disclose. M.J. Abramson reports an investigator-initiated grant to conduct the BOLD study in Australia from the National Health and Medical Research Council during the conduct of the study; and investigator-initiated grants for unrelated research from Pfizer and Boehringer Ingelheim, personal fees for unrelated consultancies and assistance with congress attendance from Sanofi, and a speaker's fee from GlaxoSmithKline, outside the submitted work. D.P. Johns has nothing to disclose. A.L. James has nothing to disclose. M. Hunter has nothing to disclose. A.W. Musk has nothing to disclose. N. Berend is a part-time employee of GlaxoSmithKline. C.S. Farah has nothing to disclose. D.G. Chapman has nothing to disclose. C. Thamrin has a patent WO 2006130922 A1 issued, which is broadly relevant to the work. In addition, she has intellectual property arrangements with Thorasys, Thoracic Medical Systems and Restech srl relating to research collaborations, but does not have any financial relationships with either company. G.G. King reports intellectual property arrangements covering research collaborations and provision of FOT devices for research from Restech during the conduct of the study; fees for consultancy services (which include lectures and advisory board services), conference attendance support and unrestricted research grants from AstraZeneca, Boehringer Ingelheim, CycloPharm, GlaxoSmithKline, Novartis, Menarini and MundiPharma, and research grants and fellowships from the National Health and Medical Research Council, the Asthma Foundation and philanthropic donations via Sydney University, outside the submitted work. 
Support statement: This study was supported by the National Health and Medical Research Council Cooperative Research Centre for Asthma and Airways (grants \#512387 and \#457385). Funding information for this article has been deposited with the Crossref Funder Registry.

\section{References}

1 Calverley PMA, Burge PS, Spencer $\mathrm{S}$, et al. Bronchodilator reversibility testing in chronic obstructive pulmonary disease. Thorax 2003; 58: 659-664.

2 Ulrik CS, Frederiksen J. Mortality and markers of risk of asthma death among 1,075 outpatients with asthma. Chest 1995; 108: 10-15.

3 Pascoe S, Wu W, Zhu C-Q, et al. Bronchodilator reversibility in patients with COPD revisited: short-term reproducibility. Int J Chron Obstruct Pulmon Dis 2016; 11: 2035-2040.

4 Nisar M, Earis JE, Pearson MG, et al. Acute bronchodilator trials in chronic obstructive pulmonary disease. Am. Rev Resp Dis 1992; 146: 555-559.

5 Rabe KF, Martinez FJ, Ferguson GT, et al. Triple inhaled therapy at two glucocorticoid doses in moderate-to-very-severe COPD. N Engl J Med 2020; 383: 35-48.

6 Bleecker ER, Emmett A, Crater G, et al. Lung function and symptom improvement with fluticasone propionate/salmeterol and ipratropium bromide/albuterol in COPD: Response by beta-agonist reversibility. Pulm Pharmacol Ther 2008; 21: 682-688.

7 Marín JM, Ciudad M, Moya V, et al. Airflow reversibility and long-term outcomes in patients with COPD without comorbidities. Respir Med 2014; 108: 1180-1188.

8 Deesomchok A, Webb KA, Forkert L, et al. Lung hyperinflation and its reversibility in patients with airway obstruction of varying severity. COPD 2010; 7: 428-437.

9 King GG, Bates J, Berger Kl, et al. Technical standards for respiratory oscillometry. Eur Respir J 2020; 55: 1900753.

10 da Costa GM, Faria AC, Di Mango AM, et al. Respiratory impedance and response to salbutamol in healthy individuals and patients with COPD. Respiration 2014; 88: 101-111.

11 Lutchen KR, Gillis H. Relationship between heterogeneous changes in airway morphometry and lung resistance and elastance. J Appl Physiol 1997; 83: 1192-1201.

12 Thorpe CW, Bates JH. Effect of stochastic heterogeneity on lung impedance during acute bronchoconstriction: a model analysis. J Appl Physiol 1997; 82: 1616-1625.

13 Bhatawadekar SA, Leary D, Vd L, et al. Reactance and elastance as measures of small airways response to bronchodilator in asthma. J Appl Physiol 2019; 127: 1772-1781.

14 Borrill ZL, Houghton CM, Tal-Singer R, et al. The use of plethysmography and oscillometry to compare long-acting bronchodilators in patients with COPD. Br J Clin Pharmacol 2008; 65: 244-252.

15 Cottee A, Seccombe L, Thamrin C, et al. Bronchodilator response assessed by the forced oscillation technique identifies poor asthma control with greater sensitivity than spirometry. Chest 2020; 157: 1435-1441.

16 Yaegashi M, Yalamanchili VAK, Kaza V, et al. The utility of the forced oscillation technique in assessing bronchodilator responsiveness in patients with asthma. Respir Med 2007; 101: 995-1000.

17 Frantz S, Nihlen U, Dencker M, et al. Impulse oscillometry may be of value in detecting early manifestations of COPD. Respir Med 2012; 106: 1116-1123.

18 Saadeh C, Saadeh C, Cross B, et al. Advantage of impulse oscillometry over spirometry to diagnose chronic obstructive pulmonary disease and monitor pulmonary responses to bronchodilators: An observational study. SAGE Open Med 2015; 3: 2050312115578957.

19 Young HM, Guo F, Eddy RL, et al. Oscillometry and pulmonary MRI measurements of ventilation heterogeneity in obstructive lung disease: relationship to quality of life and disease control. J Appl Physiol (1985) 2018; 125: 73-85.

20 Svenningsen S, Kirby M, Starr D, et al. Hyperpolarized ${ }^{3} \mathrm{He}$ and ${ }^{129} \mathrm{Xe}$ MRI: differences in asthma before bronchodilation. J Magn Reson Imaging 2013; 38: 1521-1530.

21 Oostveen E, Boda K, van der Grinten CP, et al. Respiratory impedance in healthy subjects: baseline values and bronchodilator response. Eur Respir J 2013; 42: 1513-1523.

22 Toelle BG, Xuan W, Bird TE, et al. Respiratory symptoms and illness in older Australians: the burden of obstructive lung disease (BOLD) study. Med J Aust 2013; 198: 144-148.

23 Buist AS, McBurnie MA, Vollmer WM, et al. International variation in the prevalence of COPD (The BOLD Study): a population-based prevalence study. Lancet 2007; 370: 741-750.

24 Jetmalani K, Chapman DG, Thamrin C, et al. Bronchodilator responsiveness of peripheral airways in smokers with normal spirometry. Respirology 2016; 21: 1270-1276.

25 Brown NJ, Xuan W, Salome C, et al. Reference equations for respiratory system resistance and reactance in adults. Respir Physiol Neurobiol 2010; 172: 162-168.

26 Salome CM, Thorpe CW, Diba C, et al. Airway re-narrowing following deep inspiration in asthmatic and nonasthmatic subjects. Eur Respir J 2003; 22: 62-68. 

measurements in school-aged children. Respir Physiol Neurobiol 2011; 177: 199-206.

28 Dellaca RL, Santus P, Aliverti A, et al. Detection of expiratory flow limitation in COPD using the forced oscillation technique. Eur Respir J 2004; 23: 232-240. asthma. Br J Clin Pharmacol 2005; 59: 152-159. tiotropium and ipratropium bromide; a randomized, double-blind, placebo-controlled, cross-over study in healthy subjects. Br J Clin Pharmacol 2006; 61: 398-404.

33 Wesseling G, Vonk HM, Wouters EFM. Effects of inhalation of beta 2-sympathicomimetic and anticholinergic agents on the impedance of the respiratory system in normal subjects. Chest 1990; 97: 1137-1140.

34 Thamrin C, Gangell CL, Kusel MMH, et al. Expression of bronchodilator response using forced oscillation technique measurements: absolute versus relative. Eur Respir J 2010; 36: 212.

35 Milne S, Jetmalani K, Chapman DG, et al. Respiratory system reactance reflects communicating lung volume in chronic obstructive pulmonary disease. J Appl Physiol (1985) 2019; 126: 1223-1231.

36 Eddy RL, Westcott A, Maksym GN, et al. Oscillometry and pulmonary magnetic resonance imaging in asthma and COPD. Physiol Rep 2019; 7: e13955.

37 Woodruff PG, Barr RG, Bleecker E, et al. Clinical significance of symptoms in smokers with preserved pulmonary function. N Engl J Med 2016; 374: 1811-1821.

38 Dellaca RL, Pompilio PP, Walker PP, et al. Effect of bronchodilation on expiratory flow limitation and resting lung mechanics in COPD. Eur Respir J 2009; 33: 1329-1337.

39 Zerah F, Lorino AM, Lorino $\mathrm{H}$, et al. Forced oscillation technique vs spirometry to assess bronchodilatation in patients with asthma and COPD. Chest 1995; 108: 41-47.

40 Zimmermann SC, Watts JC, Bertolin A, et al. Discrepancy between in vivo and in vitro comparisons of forced oscillation devices. J Clin Monit Comput 2018; 32: 509-512.

41 Dandurand RJ, Lavoie JP, Lands LC, et al. Comparison of oscillometry devices using active mechanical test loads. ERJ Open Res. 2019; 5: 00160-2019. 